\title{
Alexander's Grammar Teaching Method in New Concept English
}

\author{
Xinghua Zhao \\ Huaqiao University, Quanzhou 362000, China. \\ 50880865@qq.com
}

Keywords: New Concept English, covert grammar teaching, sentence writing.

\begin{abstract}
This paper explores L.G. Alexander's English grammar teaching method in New Concept English (NCE), for the two reasons as follows: (a) NCE's popularity in China and (b) my personal appreciation for the grammar teaching method applied in NCE. The paper specifically focuses on the analysis of Alexander's grammar teaching, recognizing it as a covert grammar teaching method and discusses the advantage and disadvantage of this grammar teaching.
\end{abstract}

\section{Introduction}

New Concept English is a set of course books written and edited by L.G. Alexander with an aim to 'lead the adult and secondary school student who is an absolute beginner to fluent English through four integrated books [1967 Book 3: backcoverpage.' The course was first published on October 30, 1967.It consists of four books. Each book has its own basic aim, intended student and assumed knowledge which are in accord with corresponding level of the student. The new concept introduced by Alexander to achieve is particularly " that of the multi-purpose text which is used as a basis for aural comprehension, oral practice, reading, oral composition, dictation, controlled comprehension, précis and composition practice and written grammar exercises in recall' [Alexander 1967 Book3 : coverage 2].

Since a collaborative edition of New Concept English with Chinese notes was published in China at the end of 1997, it has sold nearly 1.5 million copies during the first four year of publication. After that, it has undergone several reprints to satisfy the needs of different levels and different types of English learner. For decades, its followers share their learning experience and data on the internet which provides an easy and cost-effective solution to learners' puzzles encountered. That in turn contributes to the popularity of New Concept English in China.

\section{NCE'S Grammar Teaching Method}

Analysis of Alexander's grammar teaching method is focused in this part. It will include two parts, first, the general review his grammar teaching in the whole set of books; secondly, the advantage and disadvantage of his method.

\subsection{The Role of Grammar in Teaching-Covert to Overt.}

In NCE, Alexander uses 'key structure' to indicate essential grammar and 'special difficulties' to present the usage. However, there is little explanation either in 'key structure' or in 'special difficulties'. All the grammatical points are presented in certain structural patterns. According to Hammer, there are two kinds of grammar teaching: covert and overt.

Covert grammar teaching is where grammatical facts are hidden from the students-even though they are learning the language. In other words, the students may be asked to do an information gap activity or read a text where new grammar is practiced or intruded, but their attention will be drawn to the activity or to the text and not to the grammar.

Overt grammar teaching means that the teacher actually provides the students withgrammatical rules and explanations - the information is openly presented, in other words.

[Harmer 1987:3-4] 
Harmer [1987:4] also notes that 'in recent years the emphasis has shift away from the teaching of grammar '. Teachers concentrated more on other issues, such as how people learn language and what they want to say.

I shall analyses the grammar teaching in each book to identify Alexander's method as a whole. In Book 1, only 7 out of 144 texts appear as short passages, the rest are presented as dialogues. No grammatical rules or explanations are provided in Book 1. A heavy emphasis is placed on listing and speaking. The teaching of grammar at this stage is fairly covert since the main aim is to get students practice and use the language as much as possible.

It is expected that the balance would change as the students learn more. In Book 2, grammatical terms such as the present continuous, the simple present, and the present perfect begin to appear. The ability to recognize them and learn to form some certain items is required, e.g.: elementary uses of the verbs be and have in the present and past. Exercises like 'give the correct form of verbs' is given to help student have grip on the required items. Nevertheless, like in Book 1, no detailed explanations of these items are presented. It is therefore clear that Alexander sticks to the covert method in Book 2.

As far as Book 3 and 4 are considered, the grammatical facts are still hidden from the students, students are asked to concentrate on certain grammar uses in the text to find out how they work to discover the grammar rules rather than be told, and then they are told to do similar writing exercises for consolidation. Book 3 focuses on certain grammatical points whilst in Book4 no use has been made of grammatical terminology, all difficult points are presented as sentence patterns and a brief explanation is followed, for instance, the use of always is introduced in a manner as the following example illustrates:

People are always talking about 'the problem of youth'.

Whenever I met him, he always talks about his personal problems.

The first sentence describes something that happens all the time; the second sentence describes something that happens frequently.

[Alexander 1967 Book 4:27]

However, this kind of explanation is also rare in Book 4, in most of cases, the grammatical points are presented in structural patterns followed by written practice (e.g. fill-ins, sentence writing).

In the teaching of grammatical throughout the NCE, students are always asked to refer to the texts when in difficulty. Alexander places heavy stress on the context and text in the teaching of grammar. This is one trend in grammar teaching:

There are also encouraging signs that leaders in the language teaching profession are beginning to acknowledge that the teaching of grammar to ESL/EFEL learner should be carried out in context with discourse or text providing the appropriate pedagogical frame

[McCarthy 1991, Widows 1990; quoted by Celle-Murcia 2000:61]

\subsection{Written Practice.}

The discussion above characterized Alexander's grammar teaching method as covert grammar teaching. In this section, practice used to build up the recognition and comprehension of grammar items is discussed. Grammar practice is often done through writing. Students are frequently given homework exercises which ask them to practice specific language items [Harmer 1987:51]. In NCE, a variety of written practice are employed to help students practice certain grammatical items: fill-ins, correct form of verbs, answering questions, sentence writing etc. These practice are based on material in the passages, answers of some exercises can be tracked back to the text. (E.g. fill-ins, correct from of verbs). The practice becomes longer and more complex as the course progresses. This characteristic is particularly demonstrated in sentence writing, different types of grammar writing practice do not co-exist in first three books but in the fourth book.

In Book3, 75\% of grammar written practice is sentence writing; whilst in Book 4, the written practice is a combination of several kinds. Sentence writing, however, occurs in every lesson as a necessary part. This practice is more diversified and complicated than the other two. With regard to the presentations in Book 3 and Book 4, they can mainly be divided into three sub-types according to the specific requirement of the writing. They are: complete sentence, rewrite sentence by changing form, write sentence with certain words or phrases. As far as the difficulty is considered, the further 
the course goes, the stricter the requirements are. The following examples illustrate the types of sentence writing in NCE:

Example 1

Complete the following:

1. If you had told me earlier...

2. You will be disappointed if...

[Alexander 1967 Book 3: 54]

Example 2

Write sentences using have with the following:

1. A smoke.2. Got a headache.3. Repaired.

[Alexander 1967 Book 3: 62]

\section{Example 3}

1. I had no sooner got off the ship than I... (I. 13). Join these pairs of sentences with no sooner ... than. (I SD 98a)

I opened the door. The telephone began to ring.

He finished his speech. Everyone began to clap.

2. Some of them were as big as marbles. (II. 17-18) Write two sentences illustrating the use of as ... as and not as ....as. (I KS 86a)

[Alexander 1967 Book 3: 62]

\section{Advantage and Disadvantage of Covert Grammar Teaching}

\subsection{Advantage.}

The advantage of using covert grammar teaching method is illustrated as follows. At the most covert level (e.g. Book 1), students are exposed to the new language, with no focus or fuss, sometime before it is. In this way, students are less likely to be scared away by a cluster of grammatical rules, which may be very different from their own language. For example, Chinese students are very often confused by subject-verb concord, students very often lose their interest in learning English if they are asked to concentrated on the grammar rules at the right beginning. As the students come to a higher level of study, they are asked to look at some sentences and say how the meaning is expressed (e.g. Book2 and 3) and what the differences are between the sentences (e.g. Book4). These processes are illustrated in written practice (see 'written practice' above) for mastering certain grammatical items. As the students puzzle through the information and solve the problem in front of them, they find out how grammar is used in a text and are actually acquiring a grammar rule. By involving the reasoning processes in the task of grammar acquisition, students are concentrating fully, using their cognitive powers. This approach, therefore, is more student-cent red: it is not just the teacher telling the students what the grammar is. They are actually discovering information for themselves.

\subsection{Disadvantage.}

Although encouraging students to discover grammar for themselves is one valuable way of helping them to get grips with the language, it is not suitable for all students at all levels. The cover approach can take a long time and can occasionally be confusing [Harmer 1987:29-30]; and so the balance of using covert method should be changed according to the different steps of study. Harmer [1978:7] suggests that covert method can be applied to advance teaching. As the students learn more, their level of English enable them to talk about grammar and to analyses its properties. However, as already noted, the covert method is consistent in New Concept English.

As NCE is particularly designed for adult students and is in fact used mostly by adults in China. These learners have jobs and thus cannot devote much time to the study of English. It is often very difficult to solve the problem and then figure out the grammar rule on their own. That is why some students complained that NCE was sometimes hard to understand, for it does not provide the grammar rule explicitly and openly. So in teaching NCE, teachers should decide when to give explanations, with what grammar, and with which students. 


\section{Conclusion}

This paper has examined Alexander's grammar teaching method in New Concept English. In NCE, Alexander uses covert grammar teaching method, he does not provide the explanations of grammatical rules in the book. With this method, students are hidden from the grammatical facts and are hoped to subconsciously absorb grammatical information which will help them to acquire the language as a whole. In NCE, grammar practice is often done through writing, being typified by sentence writing.

\section{References}

[1]. Alexander, L.G. New Concept English 3: Developing Skills. Shanghai: World Press. 1967.

[2]. Hammer, Jeremy. Teaching and Learning Grammar. London: Longman. 1987.

[3]. Alexander, L.G. New Concept English 4: Fluency in English. Shanghai: World Press. 1967.

[4]. Celle-Murcia, Marianne and Elite Olsten. Discourse and Context in Language Teaching. Cambridge: Cambridge University Press. 2000.

[5]. Alexander, L.G. and He Quoin. New Concept English 1: First Things First. Beijing: Foreign Language Teaching and Research Press. 1997.

[6]. Alexander, L.G. and He Quoin. New Concept English 2: Practice and Progress. Beijing: Foreign Language Teaching and Research Press. 1997. 